\title{
Real time model of a lock gate system upon fingerprint with microcontroller
}

\author{
Maath Jasem Mahammad, Yousif Al Mashhadany, Abdulkader Mohammad Eyada \\ Department of Electrical /College of Engineering, University of Anbar, Iraq
}

\begin{tabular}{l}
\hline \hline Article Info \\
\hline Article history: \\
Received Apr 16, 2020 \\
Revised Jun 14, 2020 \\
Accepted Jul 18, 2020 \\
\hline
\end{tabular}

\section{Keywords:}

Authentication

Enrolled

Fingerprint model

Lock gate system

Microcontroller

\begin{abstract}
Safety is one of the most important things that we are keen to provide all aspects of our lives. Keyless lock gate with fingerprint access has many advantages over traditional systems such as passwords. Therefore, fingerprint identification represents the main part, which require that system is cheap, practical, easy to use and allows fast and securely. This paper discusses the design and implementation with real time model of a practical lock gate system for the achievement of high security by using fingerprint purification to control the mechanism of opening doors in banks, warehouses, laboratories and places of interest. In this paper, the microcontroller technology in the Ardonio board was used with an optical sensor to take the fingerprint, convert it into digital data, and insert it into a definition window to unify all input data and store it for use when compared to the system experience. After obtaining the result of the comparison, the appropriate commands are prepared for operating the servo of the lock mechanism for the doors used. In the testing of the system, the results are very accurate. The system also has other advantages such as small size and low power required for operation and ease of use.
\end{abstract}

This is an open access article under the CC BY-SA license.

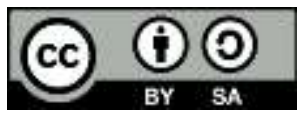

\section{Corresponding Author:}

Maath Jasem Mahammad

Department of Electrical

College of Engineering

University of Anbar, Iraq

Email: maath.mahammad@uoanbar.edu.iq

\section{INTRODUCTION}

The design of security lockgate using the fingerprint technology was built using a microcontroller, which reads from fingerprint scanner as a process of verifying the fingerprint image to open a protected door [1-4]. Fingerprint identification is one of the most reliable ways to verify a person's identity. A fingerprint is papillary patterns on the skin that are unique to each person, and unchanged throughout his live [5]. The fingers have a stream like the pattern of the ridges and valleys. Papillary edges on the finger, called rubbing edges, which help the hand to hold objects, increment grating and improve the material detecting of surface structure [6-9]. At present, the most popular method of biometric identification is fingerprint recognition. These systems are cheap, practical, wide use and have in future good development due to their adaptability [10].

In this paper we have tried to implement lock gate system by using a fingerprint scaner interfaced with Arduino microcontroller [11-13]. Any fingerprint scanner has two functions: get an image of a fingerprint, called verification and check its pattern for matching with other patterns in the database, called identification [14]. When verify, the system compares the input fingerprint with the "enrolled" fingerprint of a specific user to determine if they belong to the same finger. During identification, the system compares the 
fingerprint of the input fingerprint with the fingerprints of all registered users in the database to determine if the person is already known under a duplicate or under a false name [15-17].

A model of a fingerprint detection system is designed to work mainly on three principles: a stage of acquisition an image, stage of extraction and pattern matching. Stage imaging is the most important part; it involves obtaining an image using the fingerprint of the user interface [18-20].

User fingerprint system interface is a fingerprint scanner, through which images are acquired and stored in the database [21]. The extraction stage comprises extracting minutiae points in a fingerprint. This includes the removal of an important detail of fingerprints, and then sends it to store in the database [22]. The task of the matching stage, to compare and check pattern prints fingers the modes of operation of the system are mainly in two ways [23, 24]:

a) Enrolment/Registration mode: at this stage, called enrolment, the system measures the biometric characteristics of the user. Based on this measurement, it generates a template that is stored with any other relevant user information in protected memory or a database. After the registration phase, the user becomes available in the system so that it can be correctly identified at the second stage of the recognition process, at the authentication stage.

b) Authentication mode: at the authentication stage, the user's biometric characteristics are measured again and compared with the previously saved template. If they are similar enough, it is assumed that a previously registered is present.

c) As a result of the biometric authentication process, the system accepts or rejects the user, thereby improving the reliability and security of application against phishing attacks [25-27].

\section{DESIGN AND IMPLEMNTATION}

In this section, we describe the implementations of complete hardware/software proposed system. The hardware design combines the microcontroller/Arduino with the fingerprint module, LCD display, and interfaces. The software routines for system are implemented under the open-source Arduino software.

\subsection{Main part system}

The components required to design the system are: arduino uno, finger print module, four push button, two LEDs, power supply, plastic box, servo motor and 16x2 LCD.

\subsection{The board of arduino}

The microcontroller used in this work is Arduino/Genuino Uno, it has a USB connection and power jack with quartz crystal (16MHz), six analog inputs and 14 digital inputs pins. The Arduino board equipped with internal RTC (real time clock). A real-time clock is a clock keeps the current time and that can be used in order to program actions at a certain time. As the board is powered, the RTC is reset and starts from a standard date.

\subsection{Fingerprint optical module}

The main part of the scanner as shown in Figure 1, is a CCD device consisting of light-sensitive diodes called photosites. These sensors produce an electrical signal as much as the response to photons of light. Usually the electrical signal is generated by a small piece known as pixels relative to the light that hit the spot. The working mechanism of the scanner is to create an analog-to-digital axis by processing the analog electrical signal to create a digital representation of the image. Fingerprinting by placing the finger in a specific location on the glass plate. The CCD camera then takes a picture by using its own light source, the light-emitting diode matrix, to illuminate the tops of the fingers. An upside-down image is generated with dark areas representing the reflection of the finger waves and lighter areas representing the less reflective areas of the light. The scanner takes a number of times for the same model to have a good database. Before starting the comparison bin When you take a new image for the purpose of the test, the processor makes sure that the image under examination has high accuracy by creating a perpendicular line on the hills with successive parts of very dark pixels and pixels very light. Then, if the image is clear and known, the processor moves to the comparison role by calculating all the pixels between the two fingers to a certain extent, which represents the degree of tolerance adopted in comparison. The decision is determined positively or negatively. The PIN definition of fingerprint module shown in Table 1. 


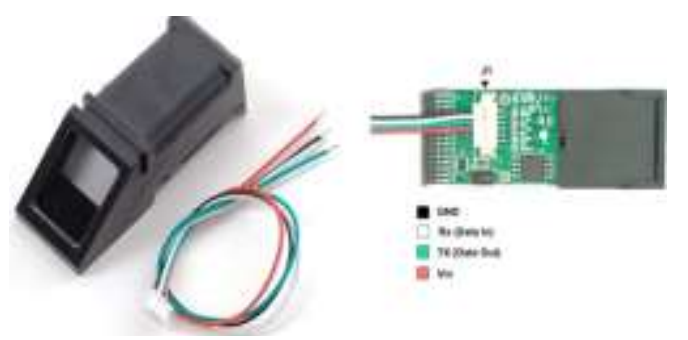

Table 1. The PIN definition of fingerprint module

\begin{tabular}{|c|c|c|}
\hline No & Name of pin & Description \\
\hline 1 & Power supply (+ve) & The main positive sources of power \\
\hline 2 & Module (Tx) & $\begin{array}{l}\text { The output of circuit used with } \\
\text { impedance around } 10 \mathrm{~K} \text { Ohm. }\end{array}$ \\
\hline 3 & Module (Rx) & The input voltage with 7V \\
\hline 4 & Power supply (-ve) & $\begin{array}{c}\text { The negative terminal of source } \\
\text { power }\end{array}$ \\
\hline
\end{tabular}

Figure 1. Fingerprint optical module

\subsection{Lock door system}

Here we attached a servo motor as shown in Figure 2, to act as a lock door gate. There are many types of Servo these depend upon the shapes and sizes. The electrical connection of the model which used in this work has there wires, the wires used for positive voltage, ground and last used in position setting.

The combination of DC motor, position control system, and gears are represents a servo motor. The control electronics apply the adjustment of position of the shaft in the DC, this process is done by duty ratio of the PWM signal.

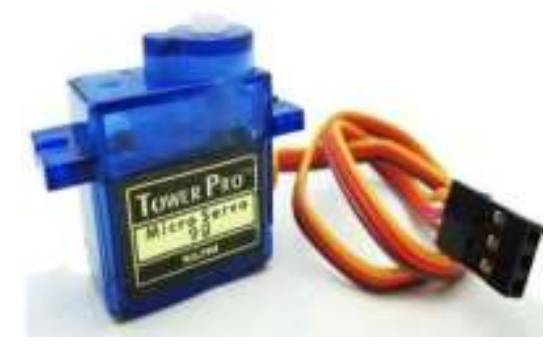

Figure 2. Servo motor

\subsection{Circuit explanation}

The schematic circuit diagram of lock gate system contains fingerprint module with Arduino microcontroller which controls whole the process of the project, push button, and LCD as shown in Figure 3. Arduino controls the complete processes. The connection of the practical model of Arduino in this work can be description by explain the connection of mean point with pins of board, where D14(ENROL), D15(DEL), D16(UP) and D17(DOWN) while the Yellow LED will connect to D6 of the board as a digital pin, and the this with respect resistance $1 \mathrm{~K} \mathrm{Ohm}$ and Green LED is connected to D6. In this connection

Rx and Tx which represent the Finger Print Module's directly connected at Digital pin D2 and D3 of Arduino. The Finger Print Module's need 5V as power supply will taken from Arduino board and Servo motor is also connected to PWM pin D5 of Arduino. A 16x2 LCD has RS, EN, D4, D5, D6, and D7 represent the configured in 4-bit mode and the connection at Digital pin D13, D12, D11, D10, D9, and D8 of Arduino.

\subsection{The flow chart of the software developed}

The flow charts of the program written in our fingerprint detection system can be divided into three mainly parts as shown in Figure 4:

a) Check serial connection between the fingerprint module and arduino board

b) The Enrolment/Registration stage

c) The Authentication/Verifying stag

According to the program flow charts, the software that drives the microcontroller was done using open-source Arduino software. The coding was segmented into various modules; first, the module that interface the fingerprint scanner with Arduino board and also drives the LCD screen; next is the module that controls the fingerprint scanner, which instructs the scanner to register users and allows to compare the entered finger print with pre-stored fingerprints. 


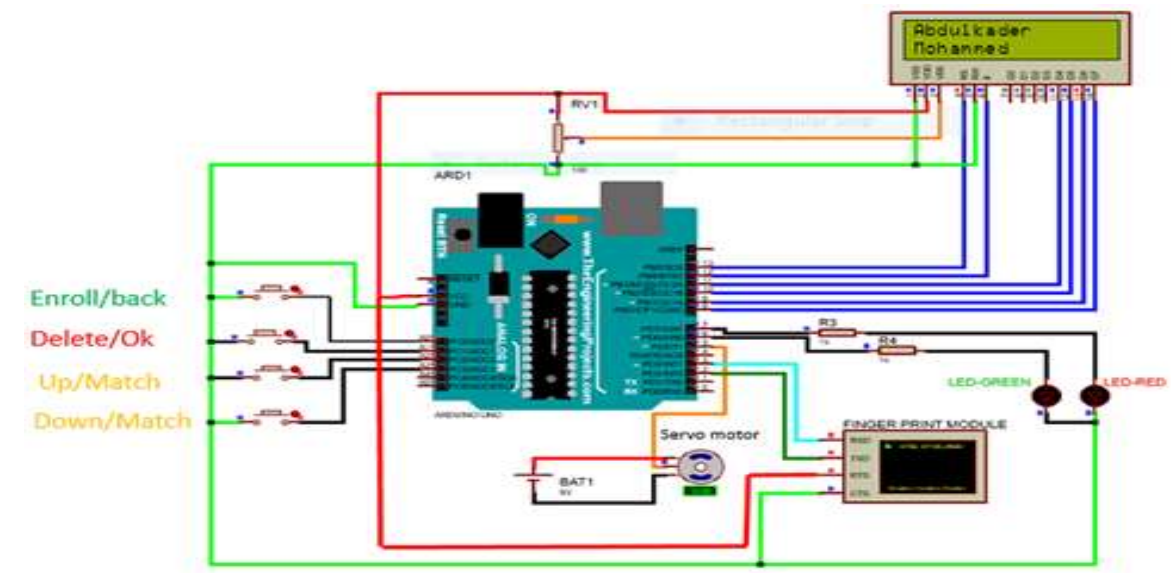

Figure 3. The schematic circuit diagram of lock gate system system

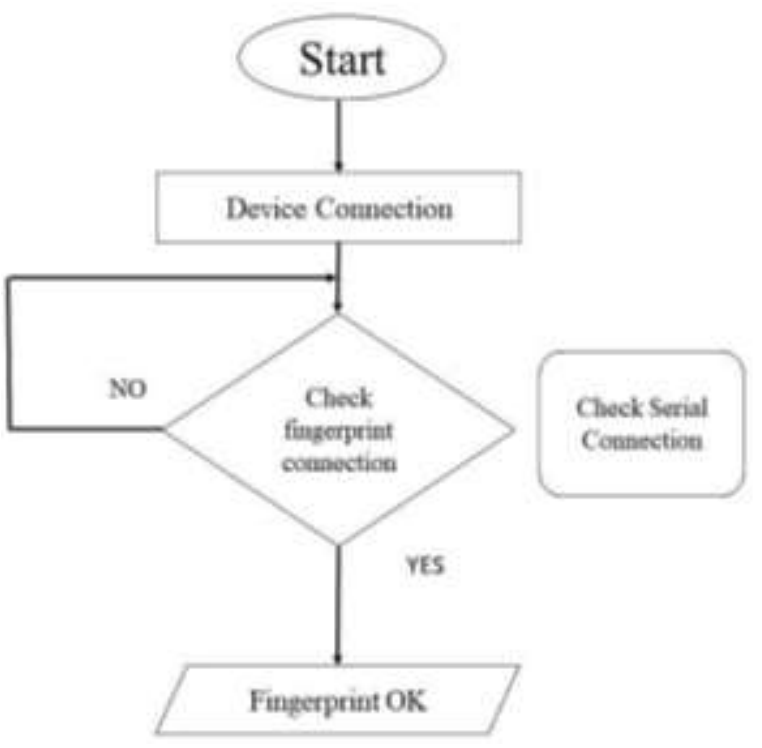

(a)

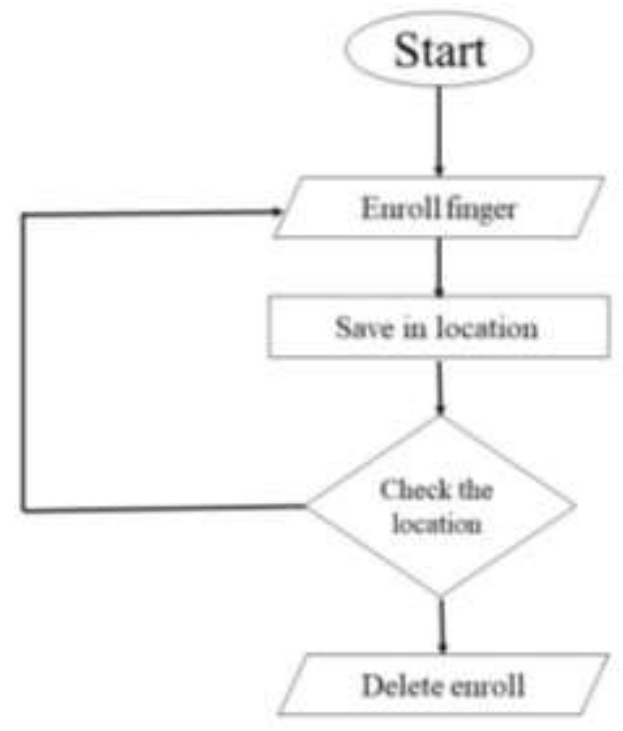

(b)

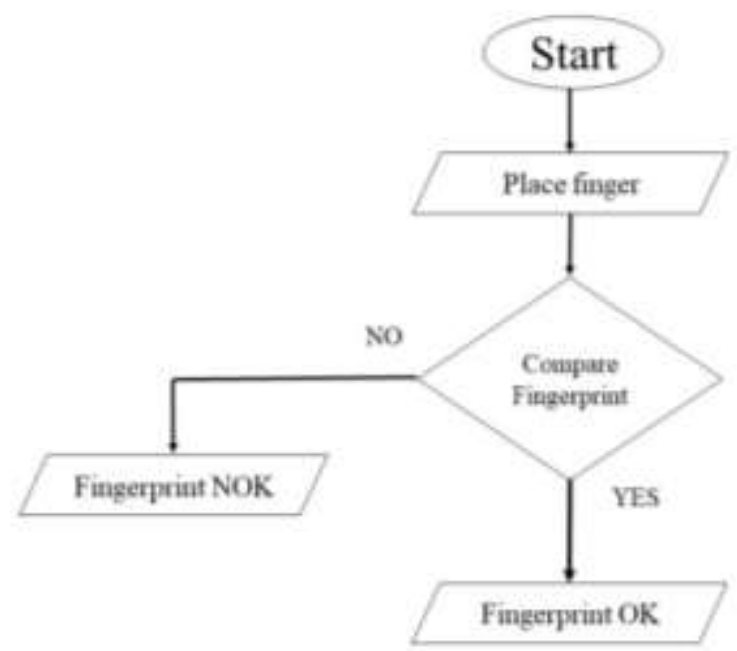

(c)

Figure 4. The flowchart of fingerprint detection system (a) check serial connection, (b) enrolment, (c) authentication 


\section{TESTS, RESULTS AND DISCUSSION}

At the beginning of the system, a statement appears on the LCD asking to press the two Up/Down keys to begin the matching process and verify the ID, as in Figure 5(a). When pressing the Up/Down key, the fingerprint sensor will be ready to take a picture of the finger and match it with the stored fingerprint. In this case the sensitive fingerprint has five attempts to take the picture if there is no finger to return to the beginning.

After the fingerprint sensor takes the fingerprint image and processes it then matches it with the fingerprint templates stored in its database, if the fingerprint is pre-stored, the matching process will succeed and the servomotor moves 180 degree, and a sentence on the LCD shows "Open Gate Allowed" as shown in Figure 5(b). If the fingerprint is not stored, the matching process will be displayed and a sentence on the LCD will appear "Finger not found". Figure 5(c) shows the process of storing the fingerprint using the Enroll button, selecting the storage location from 0 to 25 locations. Figure 5(d) shows state of deleting fingerprint and Select the fingerprint location to delete.

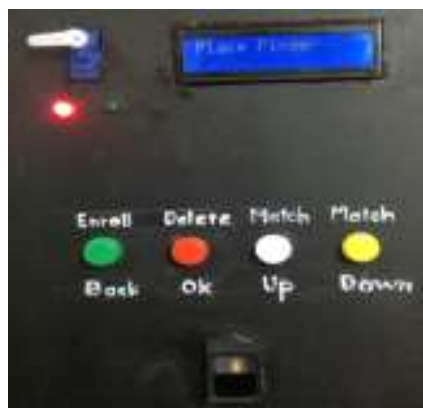

(a)

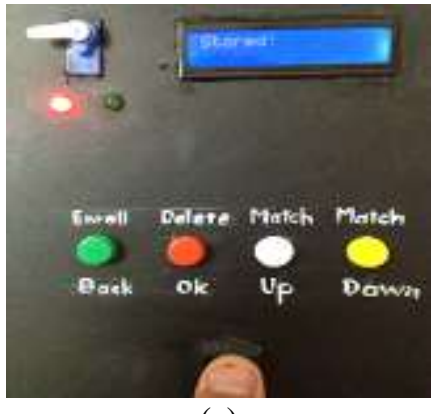

(c)

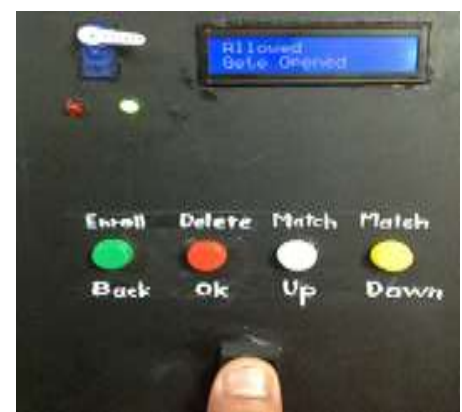

(b)

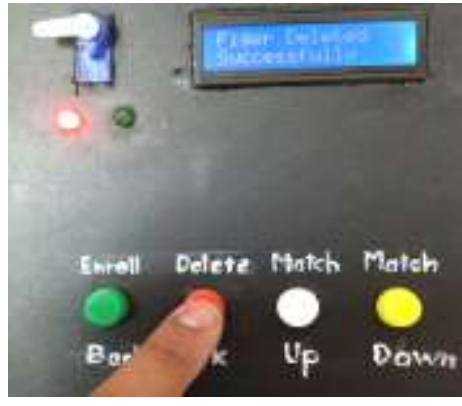

(d)

Figure 5. Lock gate system (a) starting system (b) match (c) enrolling (d) deleting

A Lock Gate Systems based Fingerprint with microcontroller are comfortable locking systems that open with just the touch of authorized user's finger; can increased use in current time, as having features:

a) High capacity of the fingerprint library, with ability of change the capacity of used Flash EEPROM

b) Acceptable security level

c) The system can use to verify persons as well as to store attendance time and date

\section{CONCLUSION}

In the industrial fields, the security aspects are sought in a very large and high degree of importance. Therefore, there are many theoretical and practical researches in this aspect. The most important things obtained in this research are the high accuracy with the high speed of implementation of the requirements such as control of lock performance and regularly. Accurate and high resolution detection of foreign fingerprints with the possibility to program dozens of fingerprints in the same model.

Through the practical experience of the designer system can be considered as an industrial model and for several applications such as control of the entry of reservoirs in banks, laboratories and important meeting rooms. The accuracy and feasibility of using the optical sensor have been proven to provide the required fingerprint data with a high degree of accuracy. There is a possibility to develop this system through several things, such as expanding the work to take a picture of the human eye instead of a fingerprint or a picture of the human face to facilitate the process of entry and exit from the gates. 


\section{REFERENCES}

[1] F.Tennyson, "Design and Implementation of a Fingerprint Lock System", IOSR Journal of Engineering (IOSRJEN) vol.7, no 4, pp. 13-19. 2017.

[2] Adeolu Afolabi, Oke Alice, "On Securing a Door with Finger Print Biometric Technique", Transact ions on Machine Learning and Arti ficial Intel l igence", vol. 2, no. 2, pp. 86-96, 2014.

[3] M. Mostafizur R. Komol, A. K. Podder, M. N. Ali, S. M. Ansary, "RFID and Finger Print Based Dual Security System: A Robust Secured Control to Access Through Door Lock Operation", American Journal of Embedded Systems and Applications, vol.6, no.1, pp. 15-22, 2018.

[4] V.Nandagopal, V.Maheswari, C.Kannan, "Vehicle Starting System Using Finger Print", International Journal of Pure and Applied Mathematics", vol. 119, no. 18, pp. 1753-1760, 2018.

[5] D. R Samuel, E. Dickson, A. B. Aaron, "Design and Implementation of A Microcontroller Based Automatic Door And Vistors", International Journal of Scientific Research And Education, vol. 2, pp 532-552, 2014.

[6] R.Sai Charan Reddy, P.Vamsi Krishna, M.Krishna Chaitanya, M.Neeharika, K Prabhakara Rao, "Security System Based on Knock-Pattern Using Arduino and GSM Communication", International Journal of Engineering and Techniques, vol. 4, pp. 154-157, 2018.

[7] N. Prince, N. Ezeilo, "Design and Implementation of Microcontroller Based Security Door System (Using Mobile Phone \& Computer Set)", Journal of Automation and Control Engineering", vol.1, no. 1, pp. 65-69, 2013.

[8] M. Amanullah, "Microcontroller Based Reprogrammable Digital Door Lock Security System by Using Keypad \& GSM/CDMA Technology", IOSR Journal of Electrical and Electronics Engineering (IOSR-JEEE), vol. 4, no. 6, pp 38-42, 2013.

[9] O. Shoewu, O. Olatinwo, "Design and Implementation of a Microcontroller Based Automatic Gate", African Journal of Computing \& ICT", vol. 6, no. 1, pp 21-32, 2013.

[10] U. James, D. E. Bassey, A. Etim, "Design and Construction of Door Locking Security System using GSM", International Journal of Engineering And Computer Science, vol. 2, no. 7, pp 2235-2257, 2013.

[11] Persis, A. Priya, "Design and Implementation of Intelligent Authentication System Based on Fingerprint, TAGA JOURNAL", vol. 14, pp 1978-1983, 2018.

[12] J. Han, "Fingerprint Authentication Schemes for Mobile Devices," International Journal of Electrical and Computer Engineering (IJECE)", vol. 5, no. 3, pp. 579-585, 2015.

[13] H. Sun, "Design of Embedded Automated Fingerprint Identification System Based on DSP", Advanced Engineering Forum, vol. 1, pp. 97-101, 2011.

[14] S. Kumar, D. Rasaily, M. Mukhia, A. Ashraf, "Biometric Attendance System using Microcontroller", International Journal of Engineering Trends and Technology (IJETT), vol. 32, no. 6, pp. 306-308, 2016.

[15] M. García, F. E. Hoyos, J. E. Candelo, " Portable and efficient fingerprint authentication system based on a microcontroller," International Journal of Electrical and Computer Engineering (IJECE), vol. 9, no. 4, pp. 2346-2353, 2019.

[16] J.Wan, L. Zhang, "Design of embedded fingerprint identification system based on TMS320C5515", Computer Science and Device System (CSSS), International Conference on 2011.

[17] K. Yadar, S. Singh, S. Pujari, P. Mishra, "Fingerprint Based Attendance System Using Microcontroller and LabView", International Journal of Advanced Research in Electrical,Electronics and Instrumentation Engineering, vol. 4, pp. 5111-5121, 2015.

[18] Y. I. Al-Mashhadany, “ANFIS-Inverse-Controlled PUMA 560 Workspace Robot with Spherical Wrist”, Elsevier Procedia Engineering journal, pp. 700-709, 2012.

[19] Annapurna Mishra, Satchidananda Dehuri, "Real-time online fingerprint image classification using adaptive hybrid techniques," International Journal of Electrical and Computer Engineering (IJECE) vol. 9, no. 5, pp. 4372-4381, 2019.

[20] Subba Reddy Borra, G. Jagadeeswar Reddy, E.Sreenivasa Reddy, "An Efficient Fingerprint Identification using Neural Network and BAT Algorithm," International Journal of Electrical and Computer Engineering (IJECE), vol. 8, no. 2, pp. 1194-1213, April 2018.

[21] Y. I. Al-Mashhadany, "Inverse Kinematics Problem (IKP) of 6-DOF Manipulator By Locally Recurrent Neural Networks (LRNNs)", International Conference on Management and Service Science (MASS 2010), pp. 24-26, Aug, 2010.

[22] S. Shinde and V. Bendre, "An Embedded Fingerprint Authentication System," International Conference on Computing Communication Control and Automation, pp. 205-208, 2015.

[23] M. Fons, F. Fons, E. Cantó., "Design of an Embedded Fingerprint Matcher System", IEEE International" Symposium on Consumer Electronics, 2006.

[24] O. A. Akinola, A. Abayomi-Alli \& R. A. Adeniyi, "Development of a Microcontroller Based Fingerprint Examination Access Control System", African Journal of Computing \& ICT Reference Format Afr J. of Comp \& ICTs, vol. 8, no. 2, pp. 145-152, 2015.

[25] Y. I. Al-Mashhadany, "Modeling and Simulation of Adaptive Neuro-Fuzzy Controller for Chopper-Fed DC Motor Drive", IEEE Applied Power Electronics Colloquium, Malaysia, pp. 110-115, 18-19 April 2011.

[26] Khin San Myint, Chan Mya Mya Nyein," Fingerprint Based Attendance System Using Arduino", International Journal of Scientific and Research Publications, vol. 8, no. 7, pp. 422-426, 2018.

[27] M. Martin, K. Štefan, F. Lubor, "Biometrics Authentication of Fingerprint with Using Fingerprint Reader and Microcontroller Arduino", TELKOMNIKA Telecommunication Computing Electronics and Control, vol. 16, no. 2, pp. 755-765, 2018. 


\section{BIOGRAPHIES OF AUTHORS}

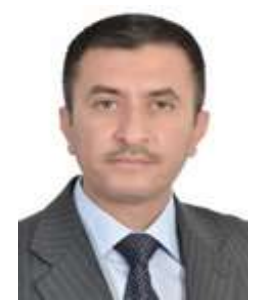

Dr. Maath Jasem Mahammad obtained B.SC. of Electrical Engineering in 1993 from AlMustansuria University, Baghdad-Iraq, M.SC. Electro-technical complex and systems of mining-enterprises in 2002 from Irkutsk State Technology University, Russia, Ph.D in 2009 System Analysis, Control and Information Processing (Information and Technical Systems) Kuban State University of Technology, Krasnodar-Russia. He is currently a lecturer at the Department of Electrical Engineering, University of Anbar, Iraq. His research interests include control and automation systems.

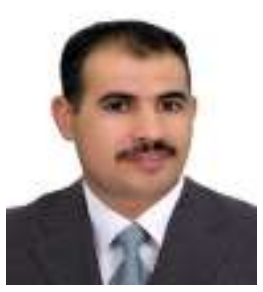

Assist. Prof. Dr. Yousif Ismail Mohammed Al-Mashhadany is a lecturer in Electrical Engineering Department - College of Engineering (Control Engineering). Senior member IEEE, He received the B.Sc. (1995), M.Sc. (1999), and Ph.D (2010) in Department of Electrical and Electronic Engineering from the Rashid School of Engineering and Science / University of Technology in Baghdad/Iraq. He complete postdoctoral fellow research in electrical engineering - control department at the University of Malaya in Malaysia (UMPEDAC) in 2012. He works since 2004, a lecturer in the Department of Electrical Engineering / Engineering College / University of Anbar. He has many publishing that included three books, two chapters, thirty seven Journals paper most of them (Clarivate, Scopus and international journal), and thirty two conferences paper.

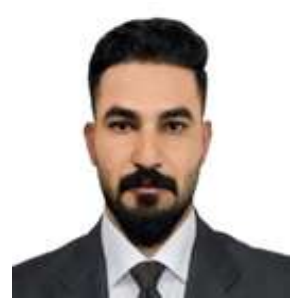

Abdukader Mohammed Eyada obtained bachelor degree of Electrical Engineering in 2018 from University of Anbar, Iraq. His work interests in field of secuerity and smart home. 